\title{
First Results of using Stem Cell Transplantation for Pediatric Patients in Case of Dilated Cardiomyopathy
}

\author{
Lacis Aris*, Bergmane Inta*, Ozolins Valts*, Lubaua Inguna***, Groma Valerija ${ }^{* * *}$, \\ Ligere Elina*, Jakobsons Eriks**, Erglis Andrejs** \\ * Clinic of Pediatric Cardiology and Cardiac Surgery, Children`s University Hospital, Riga, Latvia \\ **The Latvian Institute of Cardiology, Cell Transplantation Centre, Pauls Stradins Clinical University Hospital, Riga, Latvia \\ ***Riga Stradin's University
}

\begin{abstract}
Summary
Introduction. Dilated cardiomyopathy is a serious disorder of the myocardium in pediatric age. Conservative therapy is limited and lethal outcome observed in one third of patients within a year. Bone marrow derived progenitor cell transplantation is becoming a promising method of treatment in adult population and there is ground to believe there are perspectives in pediatric cardiology.

Aim of the Study. We present the first results of bone marrow cell transplantation in case of dilated cardiomyopathy for six patients at age four months to seventeen years.

Materials and methods. We did the six Bone marrow derived progenitor cell (BMCs) intramycardial transplantations. Five to 30 mililiters of bone marrow were aspirated from iliac bone. Seventeen to 90 million BMCs were isolated and as suspension of physiologic saline given to patients by intramyocardial punction. Every patient underwent repeated examination every two month.

Results. Six months following bone marrow derived progenitor stem cell intramyocardial transplantation we observed increase of ejection fraction in 4 patients, decrease of dilatation echocardiographycally and cardiothoracic ratio (CTR) at chest $x$-ray; decrease of the stage of heart insufficiency clinically from class IV to I-II(NYHA).

Conclusions. We see the intramyocardial administration of bone marrow cells proved to be technically feasible and safe, also the procedure does not need for expensive technical equipment. The bone marrow transplantation improves the patients clinical situation and physical measurements. Our method might be used for the stabilization of the patient to get the time for further treatment.
\end{abstract}

Key words: dilated cardiomyopathy in children, stem cell transplantation.

\section{INTRODUCTION}

Dilated cardiomyopathy is a serious disorder of the myocardium in pediatric age. The incidence of disease in population is $0.57 / 100000$ to $2.6 / 100000$. Only $1 / 4$ has identified ethyology, up to $70 \%$ of dilated cardyomyopathies are considered as idiopathic $(9,11)$. Conservative therapy is limited and lethal outcome observed in one third of patients within a year $(1,2)$. Bone marrow derived progenitor cell transplantation has been shown to improve the cardiac function in animal studies (13). Stem cell theraphy has becoming a promising therapeutical option in adult population as treatment of ischemic heart by intracoronary infusion or direct intramtocardial injection $(4,18)$. Based on various clinical studies has proven the feseablity and safety of intracoronary or intramyocardial BMCs injection for adult patients (18). There are not described large studies in pediatric cardiology but there is ground to believe there are perspectives in pediatric cardiology (6); there are described in literature only few cases of intracoronary admission of stem cells in children suffering from dilated cardiomyopathy $(12,15)$. We have chosen the intramyocardial administration of stem cells as a more technically feasible and cheaper method $(3,8)$.

\section{AIM OF THE STUDY}

We present the first results of bone marrow cell transplantation in case of dilated cardiomyopathy for six patients at age four months to seventeen years.

\section{MATERIALS AND METHODS}

We have started intramyocardial stem cell transplantation in collaboration with The Latvian Center of Cardiology, Pauls Stradins Clinical University Hospital and Cell Transplantation centre since May, 2009 ${ }^{\mathrm{Th}}$. The agreement of ethycal comitee was received. Cell suspention preparation: manufactoring is performed at The Laboratory of Cell transplantation of Pauls Stradins Clinical University Hospital. The manufacturing procedures are in compliance with principles of good manufacturing practices as set out in Directive 2003/94/EC (3 year expierence in processing biological medical products). A manufacturing authorization, Certificate No. AO-3, registration 2453/3817, including manufacturing of bone marrow derived cell therapy products. The decision to perform bone marrow progenitor cell intramyocardial implantation was made due to critical condition of the patient and no possibilities for heart transplantation. Following detailed, multiple observation of the first patient during one year, the decision to use the method in other patients was made. Allready six patients in age at 4 month to 17 year and 
weight from 5 to 61 kilograms had been admitted for the transplantation of bone marrow derived progenitor cells, three of them at age 4 month. The decreased heart function was established by 2D and 3D echocardiography: LVDd more than $2 \mathrm{~S}$ in Z-score, decreased FS $(<27 \%)$ and $\mathrm{EF}(<45 \%)$. Laboratory investgations revealed no inflammatory or autoimmune process (WBC, CRO, ANA at normal range), also genetically determined metabolic disorders were excluded, the virus (RSV, adeno, parvo B19, entero, CMV, EBV, rubella, rubeola) antibodies were negative for all of them. Transvenous endomyocardial biopsy via femoral vein was done for patient older than 1 year. The hystological investigation shows a myocite hypertrophy and fibrosis. All patients received massive anticongesstive therapy by diuretics, ACE inhibitors, carvedilol, digitalis, aspirin. Five to 30 mililiters of bone marrow was aspirated from iliac crest. Seventeen to 90 million BMCs were isolated and as suspension of physiologic saline given to patients by intramyocardial punction in two doses, each $1 \mathrm{ml}$. The injection was done by general anesthesia from subxyphoidel position through anterior wall and right ventricle cavity in myocardium of interventricular septum under echocariographyc control. Intramyocardial administration of bone marrow cells proved to be technically feasible and safe. Every patient underwent repeated examination every two month, including physical examination, electrocardiography (ECG), transthoracic echocardiography.

\section{RESULTS}

Six months following bone marrow derived progenitor stem cell intramyocardial transplantation we observed increase of ejection fraction for 4 patients (picture 1) from average basal EF was $33.66 \%$ to $50.25 \%(p<0.01)$, decrease of left ventricle dilatation echocardiographycally and CTR at chest x-ray (picture 2. and 3.); decrease of the stage of heart insufficiency clinically from class IV to II(NYHA). In biopsy section of cardiac muscle reveals a haphazard orientation of cells. Cross-striations and intercalated discs are not visible. Cytoplasmic staining and nuclei are very polymorphic. The better clinical effect observed in the patient with the worse initial status (child was discharged 26 days after BMCs transplantation with NYHA class I). We observed no side effects or heart rhytm disorders.

\section{DISCUSSION}

The current acceptable radical treatment of dilated cardiomyopathy is the heart transplantation which has a good results in perspective $(10,17)$. Unfortunately, the transplantation is limited due to absense of donors. Of course, the ventricular assisting device is the way of bridging to transplantation, but this is an expensive procedure and needs lots of resources (14). In terms of endomyocardial biopsies, the judgment is an ambiquous. The analysis of some literature data shows that endomyocardial biopsy is not suitable for diagnosis, theraphy, detection of early stages or prognostic evaluation in the dilated cardiomyopathy however another sources says that endomyocardial biopsy in children remains important in the evaluation of cardiomyopathy $(5,7)$. We believe that the need for biopsy should be carefully considered due to high risk of myocardial perforation in infants. We were trying to find the another way to improve the patients situation without possibility of transplantation. Due to absense of wide clinical studies of the stem cell application in treatment of dilated cardiomyopathy we can compare results only with few case reports. In our study we observed the increase of cardiac function like the Giessen's Justus-Liebig University and Teheran University's case results $(12,15)$. The better results were observed in younger patients and, through manipulation in the erlier period since the onset of the disease unlike those who had previously received prolonged conservative therapy only. We also noted that the vast improvement in cardiac function was observed in those patients who initially had worse results (8). That provides the basis for future research to clarify the optimal timing and possibly the age of stem cell transplantation. The question of stem cell action mechanisms is left open: direct cell implantation or paracrine effect via cytokine induced growing and increase of residual viable myocites, stimulation of resident cardiac stem cells or induction of cell fussion between transplanted bone marrow cells and resident myocites. In each case the results are promising and give hope that stem cell transplantation might be used as a method of dilated cardiomyopathy treatment or as a bridging to transplantation (16).

\section{CONCLUSIONS}

Intramyocardial administration of bone marrow cells proved to be technically feasible and safe, also the procedure does not need expensive technical equipment. The bone marrow transplantation improves the patients clinical situation and physical measurements. The results are promising and we hypothesise that bone marrow derived progenitor stem cell intramyocardial transplantation is a safe method and might be used for the stabilization of the patient to get the time for further treatment. 


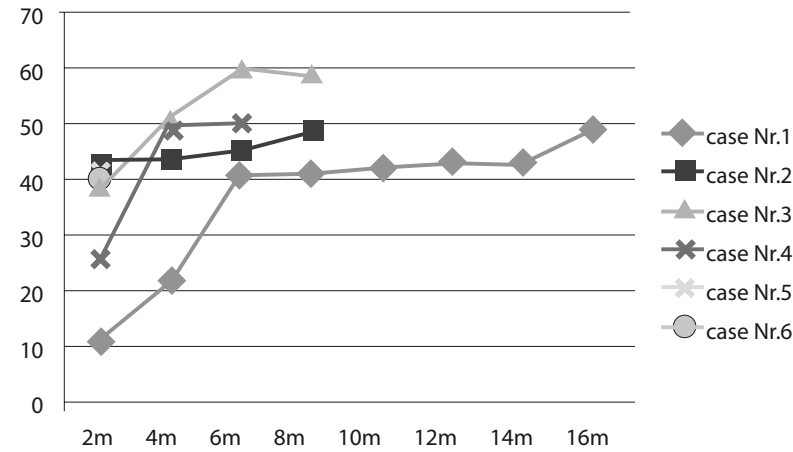

Fig. 1. The graphic of increasing of ejection fraction after BMCs transplantation. Case 1 and case 4 are 4 month old babies, case 2 - the 3 years old boy, case 3- seventeen years old girl, cases 5 and 6 not yet passed the two-month observation period after transplantation

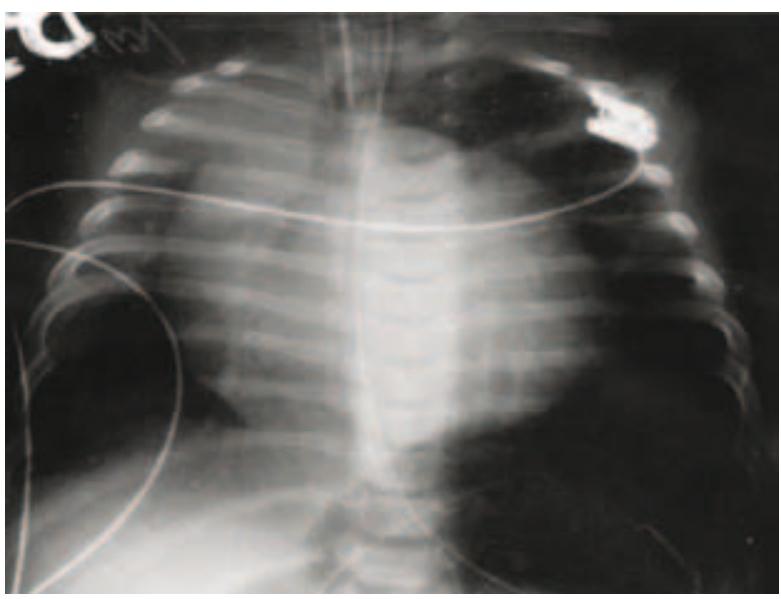

Fig. 2. The chest $x$-ray for first of patients before procedure at May,2009 shows enlarged, ball-like heart. CTI 0,75

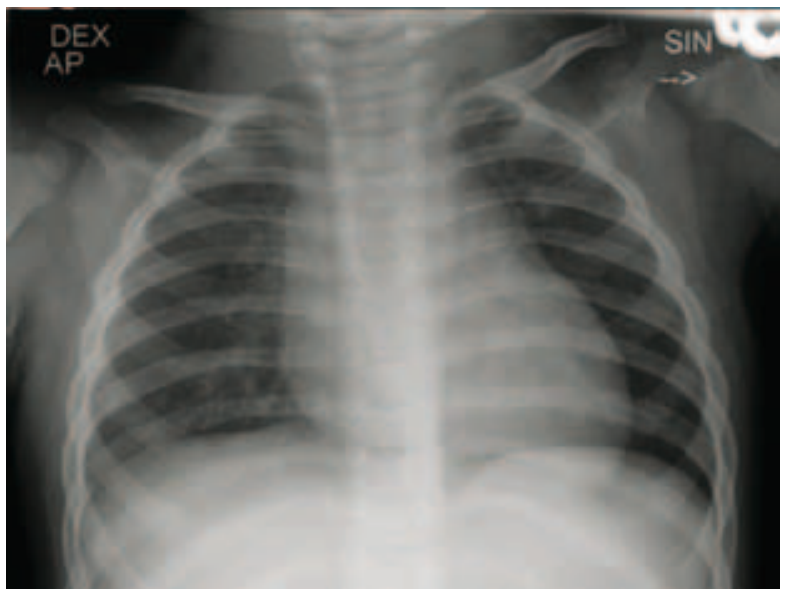

Fig. 3. The chest $x$-ray 11 months later at April,2010; almost normal heart. CTI 0.54
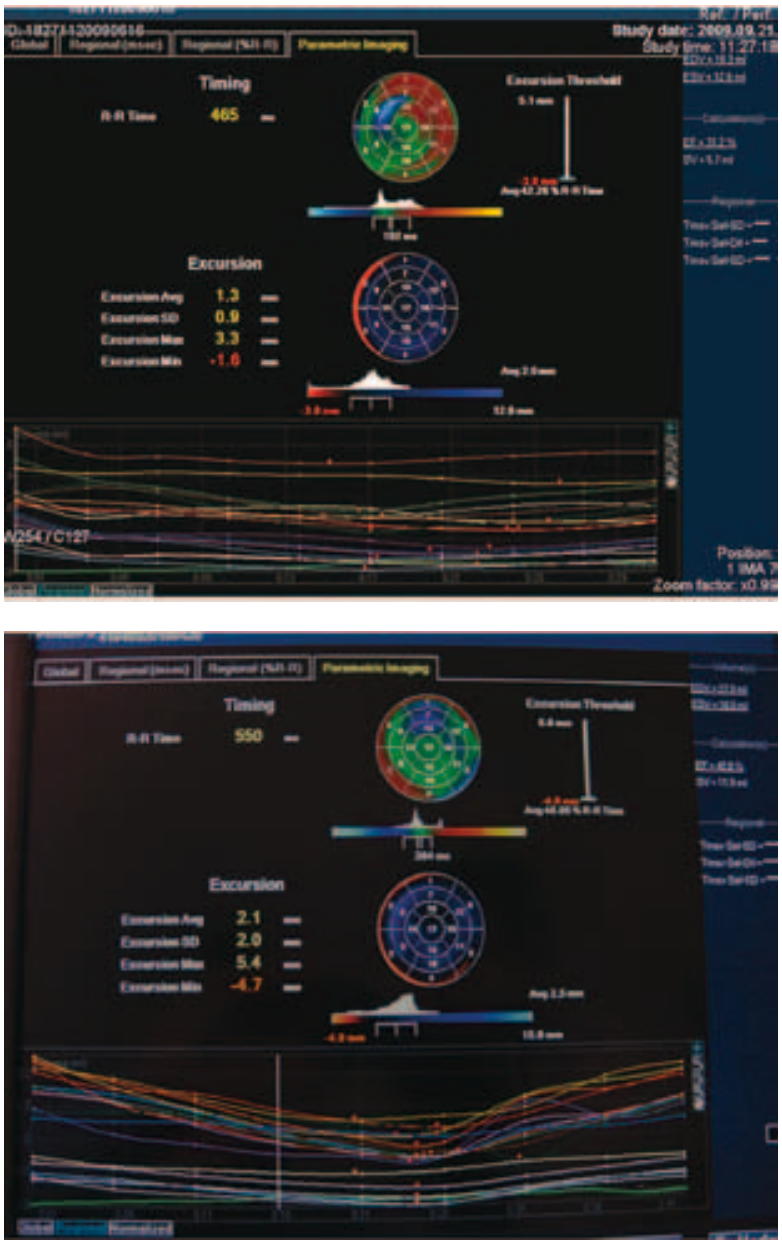

Fig. 4. Changes of excursions and decrease of dissynchronity at 3D Echo

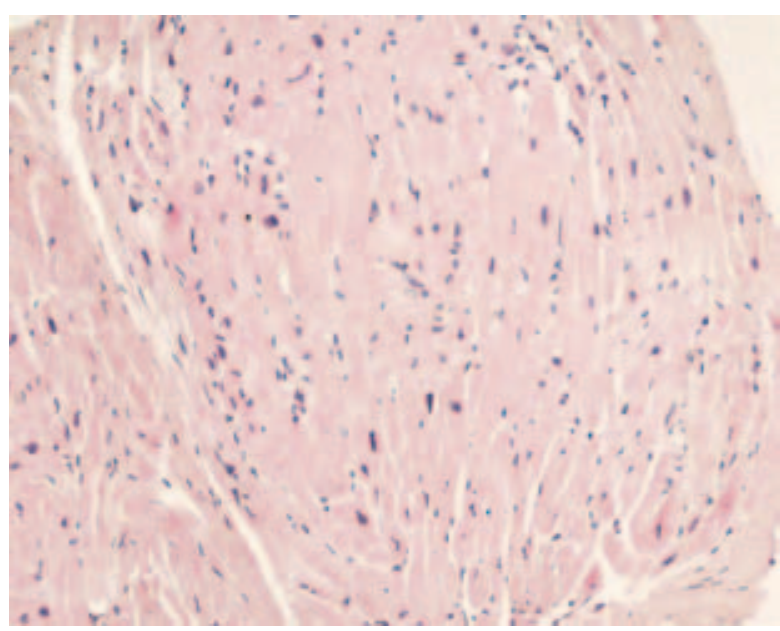

Fig. 5. Myocardial biopsy. A section of cardiac mucle reveals a haphazard orientation of cells. Cross-striations and intercalated discs are not visible. Cytoplasmic staining and nuclei are very polymorphic. H\&E, 200 


\section{Conflict of interest: None}

\section{REFERENCES}

1. Alvarez J, Wilkinson JD, Lipshultz SE. The Pediatric Cardiomyopathy Registry Study Group. Outcome predictors for pediatric dilated cardiomyopathy: A systematic review// Prog Pediatr Cardiol 2007: 25-32

2. Arola A, Tuominen J, Ruuskanen O, Jokinen E. Idiopathic dilated cardiomyopathy in children: prognostic indicators and outcome// Pediatrics, 1998;101(3 Pt 1):369-76

3. Bergmane I, Lubaua I, Ozolins V, Lacis A, Narbute I, Jegere S, Ramata-Stunda A, Jakobsons E, Erglis A. Intramyocardial Injection of Autologus Bone Marrow derived progenitor Cells in Case of Dilated Cardiomyopathy in Four Month Old Child//Cardiol Young, 2010; 20 Suppl 2:72

4. Chiu RC, Zibaitis A, Kao RL. Cellular cardiomyoplasty: myocardial regeneration with satellite cell implantation// Ann Thorac surg, 1995; 60:12-18

5. Cowley CG, Lozier JS, Orsmond GS, Shaddy RE. Safety of endomyocardial biopsy in children// Cardiol Young. 2003 Oct;13(5):404-7

6. Kaushal S, Jacobs JP, Gossett JG, Steele A, Steele P, Davis CR, Pahl E, Vijayan K, Asante-Korang A, Boucek RJ, Backer CL. Wold LE. Innovation in basic science: stem cells and their role in the treatment of paediatric cardiac failure-opportunities and challenges// Cardiol Young, 2009;19 Suppl 2:74-84

7. Kuhn H, Lawrenz T, Beer G. Indication for myocardial biopsy in myocarditis and dilated cardiomyopathy// Med Klin (Munich). 2005 Sep 15;100(9):553-61

8. Lacis A, Bergmane I, Ozolins V, Erglis A, Narbute I, Jegere S, Ramata-Stunda A, Jakobsons E. Preliminary results of using stem cells transplantation for pediatric patients in case of dilated cardiomyopathy//Cardiothor J,2010; 13 Suppl 2:S117

9. Lipshultz SE, Sleeper LA, Towbin JA, et al. The incidence of pediatric cardiomyopathy in two regions of the United States// N Engl J Med2003;348:1647-1655
10. Minami K, von Knyphausen E, Niino T, Blanz U, Tenderich G, Wlost S, Meyer H, Körfer R. Longterm results of pediatric heart transplantation// Ann Thorac Cardiovasc Surg. 2005 Dec;11(6): 386-90

11. Nugent AW, Daubeney PEF, Chondros P, et al. The epidemiology of childhood cardiomyopathy in Australia// N Engl J Med 2003;348:1639-1646

12. Olguntürk R, Kula S, Sucak GT, Ozdoğan ME, Erer D, Saygili A. Peripheric stem cell transplantation in children with dilated cardiomyopathy: preliminary report of first two cases// Pediatr Transplant. 2010;14(2):257-60

13. Orlic D, Kajstura J, Chimenti S, et al. Bone marrow cells regenerate infarcted myocardium// Nature. 2001;410:701-705

14. Pauliks LB, Undar A. New devices for pediatric mechanical circulatory support. Curr Opin Cardiol. 2008 Mar;23(2):91-6

15. Rupp S, Bauer J, Tonn T, Schachinger V, Dimmeler Z, Zeiher AM, Schranz D. Intracoronary administration of autologous bone marrow-derived progenitor cells in a critically ill two-yr-old child with dilated cardiomyopathy// Pediatr Transplant. 2009; 13(5):620-3

16. Schannwell CM. Stem cell theraphy for cardiovascular deseases. Expierence in Dusseldorf// Dtsch Med Wochenschr. 2008; 133 Suppl 8:S27409

17. Towbin JA. Cardiomyopathy and heart transplantation in children// Curr Opin Cardiol. 2002 May; 17(3):274-9.

18. Wei H M, Wong P, Hsu L F, Shim W. Human bone marrow-derived adult stem cells for postmyocardial infarction cardiac repair: current status and future directions// Singapore Med J. 2009;50(10):935

\section{Address:}

Inta Bergmane,

Clinic of Pediatric Cardiology and Cardiac Surgery,

Children`s University Hospital,

Vienibas gatve 45, LV-1004, Riga, Latvia

E-mail: intabe@navigator.lv 